\title{
Intonation in Hong Kong English and Guangzhou Cantonese-accented English: A Phonetic Comparison
}

\author{
Yunyun Ran \\ School of Foreign Languages, Shanghai University of Engineering Science, 333 Long Teng Road, Shanghai 201620, \\ China \\ Jeroen van de Weijer \\ School of Foreign Languages, Shenzhen University, 3688 Nan Hai Avenue, Shenzhen 518060, China \\ Marjoleine Sloos \\ Fryske Akademy (KNAW), Doelestrjitte 8, 8911 DX Leeuwarden, The Netherlands
}

\begin{abstract}
Hong Kong English is to a certain extent a standardized English variety spoken in a bilingual (English-Cantonese) context. In this article we compare this (native) variety with English as a foreign language spoken by other Cantonese speakers, viz. learners of English in Guangzhou (mainland China). We examine whether the notion of standardization is relevant for intonation in this case and thus whether Hong Kong English is different from Cantonese English in a wider perspective, or whether it is justified to treat Hong Kong English and Cantonese English as the same variety (as far as intonation is concerned). We present a comparison between intonational contours of different sentence types in the two varieties, and show that they are very similar. This shows that, in this respect, a learned foreign-language variety can resemble a native variety to a great extent.
\end{abstract}

Index Terms-Hong Kong English, Cantonese-accented English, intonation

\section{INTRODUCTION}

Cantonese English may either refer to Hong Kong English (HKE), or to a broader variety of English spoken in the Cantonese-speaking area, including Guangzhou (Wong et al. 2005). In practice, Cantonese English in a narrow sense (HKE) is usually not distinguished from Cantonese English in the wider sense (Wong et al. 2005). Parallel observations can be found for the native varieties. Hong Kong and Guangzhou local Cantonese dialects can be regarded as the same dialect (Zhan 2004), given that there are no massive or systemic phonological differences, either segmental or prosodic, between these varieties. However, based on some socio-cultural and lexical differences, Hong Kong Cantonese and Guangzhou Cantonese can be considered as two varieties that have undergone divergent developments from Guangzhou Cantonese since the 1970s (Zheng 1998). In this article, we examine to what extent HKE resembles Cantonese English in a wider sense. We approach this question from the angle of intonation, because this is an important marker of foreign accent (e.g. Wenk 1985), and because intonation is a complex of linguistic and paralinguistic features, reflecting a speaker's grammatical, attitudinal and social information (Shen 1990). A comparison between the intonation of HKE and Guangzhou English (GZE) will therefore be a good measuring-stick for standardization from a phonological viewpoint.

One of the characteristics that help define a variety of world English, proposed by Butler (1997), is a "standard and recognizable pattern of pronunciation handed down from one generation to another" (Butler (1997), cited in Bolton (2000)). As early as more than 30 years ago, Le Page \& Tabouret-Keller (1985) (also cited in Bolton (2000)) reported that the Hong Kong accent could be recognized easily and the local respondents had difficulty in labelling other accents of English. If HKE is indeed a standardized variety (Setter et al. 2010), at least with regard to accent (Kirkpatrick 2007), we expect the intonation to differ systematically from English spoken by Cantonese speakers outside Hong Kong - a foreign variety of English. Alternatively, if HKE is not a standardized variety, then we would not expect systematically different intonation patterns in HKE and GZE.

To investigate if HKE and GZE intonation are different or similar, we conducted an experiment on four different sentence types by Guangzhou Cantonese speakers, in English and Cantonese. We compared the outcomes with the literature on HKE intonation and on native English intonation. The results show that the intonation patterns of HKE and GZE do not differ significantly, and we will discuss how this affects the notion of standardized varieties of English.

The rest of this paper is organized as follows: we first introduce necessary background on HKE and GZE, and then provide a brief description of the relevant facts of English intonation, and Cantonese and HKE intonation. After this, we 
explain the experimental approach to the native Cantonese dialect and English of the same speakers of Guangzhou, and describe the materials, subjects and procedure. We present the result and compare intonation in HKE and native English. Finally, we discuss the results and different issues for future research.

\section{BACKGROUND INFORMATION ON CANTONESE, HKE, AND GZE}

HKE emerged from language contact with British settlers (1839-1941). However, it has been a matter of some dispute whether or not there is an autonomous indigenous variety HKE, on a par with other Englishes in the Asian region, such as Indian English and Singapore English. Some researchers have advanced arguments against this idea, arguing that Hong Kong is "a case of societal bilingualism, in which two largely monolingual communities coexist, with a small group of bilingual Cantonese functioning as linguistic middle men" (Luke \& Richards (1982), as cited in Evans (2011a)), that "English continues to remain more a foreign language than a second language to most people" (Fu (1987), as cited in Bolton (2000)), that there's "no social or cultural role for English to play among Hong Kong Chinese; it only has a role in their relations with expatriates and the outside world" (Johnson (1994), cited in Evans (2011a)), and that there is "no societal basis for a nativized variety of "Hong Kong English" (Li (1999b), as cited in Evans (2011a)), and therefore "Hong Kong has not developed a nativized variety of English" like in Singapore or India (Li 1999a). Advocates for HKE maintain that it meets at least three (Kirkpatrick 2007) or four (Bolton 2006) of the five criteria Butler (1997) proposed to define emerging varieties of English. Based on criteria including history and politics, identity construction, sociolinguistics of contact, and linguistic developments, Schneider (2007) distinguished five developmental phases for English in such contact situations in his innovative Dynamic Model: foundation, exonormative stabilization, nativization, endonormative stabilization, and differentiation. In Schneider's model, HKE already entered Phase Three (nativization) half a century ago, with heavy borrowing, local accent, and phonological, morphological and syntactic changes (Evans 2011b; Schneider 2007), as argued by Groves (2011). HKE has not reached the stage of linguistic homogeneity, including a literary tradition, of Phase Four (like Singapore English); and is not entirely standardized (as in established nations like Australia), free from external threat, with a certain amount of sociolinguistic and ethno linguistic variation emerged (Schneider 2007: 127).

The linguistic status of HKE is in this respect clearly different from GZE, where English is a foreign language that did not develop from long term language contact with a community of settlers. For instance, the influence of English in the Guangzhou Cantonese community is much smaller than in Hong Kong. In Guangzhou, teaching of English generally starts from Primary 3 (age 10) (Ye 2015), whereas the Hong Kong educational system strives for the development of trilingual (Cantonese, English, Mandarin) competences from primary school onwards (age 6-12) (Evans 2013). Due to historical, geographical, and political reasons, Mandarin is more influential in Guangzhou than in Hong Kong. For instance, the language of instruction in Guangzhou is Mandarin (Han 2012), whereas in Hong Kong it is Cantonese and English (Bolton 2000). In general, the most frequently used language in Guangzhou is Cantonese, with Mandarin as the second language and English as the third language, which definitely counts as a foreign language in Guangzhou, like in the rest of mainland China, which in terms of Kachru's paradigm shift and pluricentric model of global English, falls within the expanding circle among the 'three concentric circles' (Bolton 2000; Yi 2010).

In contrast with Hong Kong, and despite a massive amount of training, performance of mainland Chinese students in English appears to be relatively poor. Even English majors in colleges in advanced areas such as Shanghai (Bu 2016) and Guangzhou (Ye 2015) are reported to have a very low level of performance in terms of pronunciation and intonation. One of the reasons might be that there are few extracurricular chances to practice English. Ye (2015) investigated the use of English in 60 English majors who are Guangzhou natives in a Guangzhou college and demonstrated that, just like students from other areas of China, Guangzhou natives' mastery of English intonation does not transcend the elementary level and showed negative transfer effects both at the segmental and the suprasegmental level. By contrast, empirical evidence shows that English is used on a daily basis in a number of different ways in many families as well as in the professional world in Hong Kong (Bolton 2002; Evans 2011a, b). According to the 2016 census , more than $90 \%$ of the population aged over 5 in Hong Kong are able to speak Cantonese and more than 50\% of the population aged over 5 in Hong Kong are able to speak English. It is reasonable to say that in Hong Kong, English has at least an equal status with Cantonese in some domains while Mandarin has little role to play (Bolton 2000, 2011; Evans 2011b).

This suggests that the intonation of HKE and GZE may differ drastically not only because of differences in contact with British native speakers, but also just because of proficiency differences. But established varieties of English may be marked by native features as well, such that HKE and GZE have similarities. It seems that, at least at the segmental level, this is a complex matter, since HKE clearly has Cantonese segmental features alongside with British as well as American English features (Bolton \& Kwok 1990; Deterding et al. 2008; Hung 2000; Sewell \& Chan 2010). In the present paper, we will compare the intonation of HKE and GZE and investigate to what extent HKE and GZE employ Cantonese features and to what extent they resemble native English pronunciation. It will turn out that, just like for the segmental level, both Cantonese and English features can be distinguished and that the differences between HKE and GZE intonation are relatively small. Before we turn to the experimental data, we will first introduce the wider topic2017.)

"The data are available at the homepage of the Census and Statistics Department of Hong Kong: http://www.search.gov.hk/. (accessed 24 July, 
intonation in the next section.

\section{THE FUNCTION OF INTONATION}

Intonation "makes use of phonological tone for the expression of non-lexical purposes, such as phrasal structure and discourse meaning" (Gussenhoven 2004). In Pierrehumbert's (1980) system for the autosegmental representation of tones, English intonation phrases (IP) can be marked by one or a pair of pitch accents $\left(\mathrm{L}^{*} / \mathrm{H}^{*}\right)$ on the most prominent stressed syllable(s) and two extra tones that mark the phrase boundary: a phrase accent $\left(\mathrm{L}^{-} / \mathrm{H}^{-}\right)$that occurs shortly after the nuclear stress (nuclear is the most prominent in an IP) and a sentence-final boundary tone (either L\% or H\%). There is a difference in the role that intonation plays in non-tonal languages (e.g. English) and in tone languages (e.g. Chinese): intonation tends to be more complex in the former than the latter (Gussenhoven \& van der Vliet 1999), because the functional load for pitch in non-tonal languages is used mostly to convey pragmatic information at the phrasal level, whereas in tone languages it is taken up largely by the lexical tones, which distinguish lexical meanings at the word level (Everett et al. 2016; Tench 2015). The decomposition of English intonation into pitch accents, phrase accents, and boundary tones by Pierrehumbert makes it possible to study the interaction of different kinds of tones in the same system.

The relation between intonation and sentence type is not a defining one. But there is some correlation between the intonation contours and sentence types (Beckman \& Hirschberg 1994). For example, L\% is the essential property of unmarked statement intonation (Bartels 2013; Hirst \& Di Cristo 1998) while H\% denotes the need for further specification (Bartels 2013), typically in questions.

Perhaps the four most typical sentence types distinguished for different intonation contours are statements, whquestions, yes-no questions, and echo questions, because these sentence types are distinguished by intonation-the phonological alignment of tones to convey grammatical as well as pragmatic meanings - as well as by syntactic structure (Collins \& Mees 2003). Statements refer to neutral sentences (Bartels 2013), e.g., 'Lucy is in the park'. Whquestions use interrogative wh-words such as what, where, when, how, etc. to raise a question to which an answer is expected, e.g., 'How can I get to the park?' Yes-no questions are formed by inserting the auxiliary verb do or by preposing the auxiliary verb, e.g., 'Is Lucy in the park?' Such questions generally seek for confirmation and require yes or no as the answer. Echo questions are formed from statements by adding a question mark, seeking confirmation, or expressing incredulity or surprise, e.g., '(Really?) Lucy is in the park?'

Apart from accents and boundary tones, intonation contours can be marked by declination or global raising. Declination refers to the general downtrend of F0 observed over the course of an utterance (Cohen \& Collier 1982; Strik \& Boves 1995). It is natural for the slope of declination to be less steep if the utterance is longer. Declination is not universal. For some languages, including Dutch (van Heuven \& Haan 2002), suspension of declination is used to mark yes-no questions and echo questions, although this is not the case in English (Cruttenden 1997). Declination is found in all four basic sentence types in English. The steepness of declination is proved to correlate negatively with sentence length in English, as well as in Mandarin (Huang et al. 2009). Global raising refers to the local upward shift in the F0 space in yes-no and echo questions stretched over a particular domain, which is the final sequence of the phrase accent and boundary tone (Pierrehumbert 1980). This upward shift is related to the level at which the same words would appear in a statement, even if the effect of an overall higher register in questions is cancelled out (Clements 1990).

Since boundary tones, declination and global raising differ typologically between languages, transfer effects on nonnative language commonly occur. There have been studies on the English intonation spoken by Hong Kong Cantonese speakers, and some differences are found in boundary tone, declination, and global raising between Hong Kong English and native English (Chen \& Mok 2015; Cheung 2009; Gussenhoven 2012, 2014; Mok 2011; Mok et al. 2013; Setter 2003; Setter et al. 2010). Previous scholars suggest these differences might be attributed to the native language in Hong Kong, i.e. Cantonese. The intonational systems of English, Cantonese and Hong Kong English will be discussed in the next three subsections, respectively.

\section{English intonation}

Neutral declarative contour of statements in English has declination and ends with a low phrase accent which proceeds a low boundary tone (Beckman \& Ayers 1997; Beckman \& Hirschberg 1994; Jun 2006; Pierrehumbert 1980), as in (1).

$$
\begin{aligned}
& \text { Lucy is in the park } \\
& \mathrm{L}^{-} \mathrm{L} \%
\end{aligned}
$$

Wh-questions usually have declination too (Brown et al. 2015; Safárová \& Swerts 2004). Furthermore, they are marked by a high initial boundary tone on the question word and either a high or low final boundary tone (Collins \& Mees 2003; Crystal 1976), as in (2). The former sounds friendly and evocative; the latter more distant and business-like (Collins \& Mees 2003). Frequently, a fall is realized on an auxiliary verb (Collins \& Mees 2003).

$$
\begin{aligned}
& \text { a. How can I get to the park? } \\
& \% \mathrm{H}\left(\mathrm{L}^{*} \text {, optional) } \mathrm{L}^{-} \mathrm{H} \%\right. \\
& \text { b. How can I get to the park? } \\
& \% \mathrm{H}\left(\mathrm{L}^{*} \text {, optional) } \mathrm{L}^{-} \mathrm{L} \%\right.
\end{aligned}
$$

The F0 in yes-no questions (like: 'is Lucy in the park?') rises after the initial accented syllable (Lucy) so that the 
following non-stressed syllables fall more slowly than in statements: this leads to a general higher F0 level of yes-no questions than in statements. The canonical yes-no question contour has a final high phrase accent and a high boundary tone (Beckman \& Ayers 1997; Beckman \& Hirschberg 1994; Pierrehumbert 1980). In yes-no questions, a high fall + rise is common (Collins \& Mees 2003). The fall is often on the auxiliary verb (Collins \& Mees 2003), like in whquestions. The result is a global raising: there is a declination like in the statement and the phrase boundary $\mathrm{H}^{-} \mathrm{H}^{-}$ generates an F0 contour high above the generally falling pattern (Pierrehumbert 1980) as shown in (3).

$$
\begin{array}{lc}
\text { Is } & \text { Lucy in the park? } \\
\mathrm{H}^{*} \mathrm{~L}^{-} & \mathrm{H}^{-} \mathrm{H} \%
\end{array}
$$

Echo questions have the same syntactic form as statements but the intonation is characterized by global raising, a high phrase accent on the final word and a high boundary tone indicating either incredulity or seeking confirmation (Cruttenden 1997), see (4).

$$
\text { Really? Lucy is in the park? }
$$

\section{$\mathrm{H}^{-} \mathrm{H} \%$}

Table 1 summarises the points made about English intonation.

TABLE 1 .

NATIVE ENGLISH INTONATION (NA MEANS 'NOT APPLICABLE’; $\uparrow$ FOR RISE, $\downarrow$ FOR FALL)

\begin{tabular}{|l|l|l|l|l|}
\hline English Intonation & Declination & Boundary & Place of final rise/fall & Global raising \\
\hline Statements & Yes & L\% & After the last accented syllable $\downarrow$ & NA \\
\hline Wh-questions & Yes & H\% or L\% & The final $\mathrm{L}^{-} \downarrow$ & NA \\
\hline Yes-no questions & Yes & $\mathrm{H} \%$ & The first accented syllable $\uparrow$ & Yes \\
\hline Echo questions & Yes & $\mathrm{H} \%$ & The final $\mathrm{H}^{-} \uparrow$ & Yes \\
\hline
\end{tabular}

$H K C$

As mentioned earlier, Cantonese is a tone language and as such sentence intonation plays less of a role (Gussenhoven \& van der Vliet 1999). Cantonese has a relatively large lexical tone inventory, but, unlike Standard Chinese, it has no neutral tones (Wong et al. 2005). The tonal systems of Hong Kong and Guangzhou Cantonese differ only minimally, as shown in Table 2 (based on Wong et al. (2005) and Zhan (2004)).

\begin{tabular}{|c|c|c|c|c|c|}
\hline \multicolumn{2}{|c|}{ Tone description } & \multicolumn{2}{|c|}{ Open syllables } & \multicolumn{2}{|c|}{ Closed syllables } \\
\hline & & Hong Kong & Guangzhou & Hong Kong & Guangzhou \\
\hline \multirow[t]{4}{*}{ Level } & High & 55 & 55 & 5 & 5 \\
\hline & Mid-high & 33 & 33 & 3 & 3 \\
\hline & Mid-low & 22 & 22 & 2 & 2 \\
\hline & Low & & $11^{*}$ & & \\
\hline \multirow[t]{2}{*}{ Rising } & High & 335 & 335 & 35 & \\
\hline & Low & 223 & 113 & & \\
\hline \multirow[t]{2}{*}{ Falling } & Low & 221 & 221 & 21 & \\
\hline & High & \multicolumn{2}{|c|}{$553 * *$} & & \\
\hline
\end{tabular}

TABLE 2 .

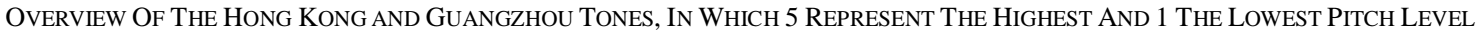

In Cantonese, particles play a major role in the expression of phrasal meaning, and 'compete' with this function of sentence intonation (see above) (see e.g. Fry 1968, as cited in Bauer \& Benedict 1997, among many others). For example, the final particle $m a$ is a question marker. Similarly, the positive plus negative syntactic structure (e.g. shi bu $s h i$ 'be not be' or you mei you 'have not have') marks yes-no questions.

The intonational markers in Cantonese are simpler than in English. Every sentence type has declination in Hong Kong Cantonese (similar to English) (Fox et al. 2008). Statements in Cantonese have a low boundary tone (Chen \& Mok 2015; Han 2013). Wh-questions typically show a declination of the F0 contour similar to that of statements (Chen \& Mok 2015; Wong et al. 2005). Typically, boundary tones in both statements and questions start no earlier than the last syllable (Chen \& Mok 2015; Xu \& Mok 2011). Yes-no questions have an optional final rise (Chow 2002, as cited by Chen \& Mok 2015). Echo (or intonation) questions are marked by an overall higher F0 level than statements and a high final boundary tone (Han 2013): the tones of the final syllable in echo questions begin at an F0 level lower than the initial and medial syllables, but rise to a level above that of the initial syllable, regardless of the canonical tone (Ma et al. 2006). The same was observed by Wong et al. (2005), who, in addition, distinguished a high boundary tone with a plateau $\mathrm{H}: \%$ (which expresses incredulity) from a regular $\mathrm{H} \%$ (which expresses seeking confirmation). There is an abrupt final rise and expansion of pitch to the speaker's largest range at the final boundary tone (Han 2013; Vance 1976). 
There is no global raising in Hong Kong Cantonese echo questions (Han 2013; Xu \& Mok 2011). The F0 contours of statements and echo questions in Cantonese typically overlap until the last syllable (Chen \& Mok 2015). Table 3 gives the main intonational characteristics of the different sentence types in Hong Kong Cantonese.

TABLE 3.

HONG Kong CANTONESE INTONATION (NA MEANS 'NOT APPLICABLE’; $\uparrow$ FOR RISE, $\downarrow$ FOR FALL)

\begin{tabular}{|l|l|l|l|l|}
\hline Cantonese Intonation & Declination & Boundary & Place of final rise/fall & Global raising \\
\hline Statements & Yes & L\% & Final syllable $\downarrow$ & NA \\
\hline Wh-questions & Yes & H\% or L\% & Second part of the last syllable $\uparrow$ & NA \\
\hline Yes-no questions & Yes & Optional H\% & Second part of the last syllable $\uparrow$ & No \\
\hline Echo-questions & Yes & H\% & Final syllable $\uparrow$ & No \\
\hline
\end{tabular}

\section{HKE intonation}

In this subsection, we describe the declination, boundary tone and global raising of four different intonation contour patterns in statements, wh-questions, yes-no questions, and echo questions in HKE, based on the existing literature.

The F0 contours of statements, yes-no questions, and echo questions in HKE typically overlap until the penultimate syllable, from where $\mathrm{H} \%$ in questions starts to deviate from the unmarked L\% contour in statements (Chen \& Mok 2015). As a result of this, the three sentence types have the same degree of declination, without global raising.

For statements in HKE, there is no consensus about whether there is a final low boundary tone or not. Chen \& Mok (2015) observed L\%, but Gussenhoven (2014) observed two intonation contours for words with penultimate or earlier stress - a final L\% or no boundary tone (which is typical in this language (Gussenhoven 2012)), because of an L\% deletion rule (see example in (5)).

The park is open.

$$
\mathrm{L}^{-} \%
$$

$\mathrm{L} \% \rightarrow \varnothing / \mathrm{L} \_\quad$ (L\%-deletion after a low tone)

A level tone after the IP-final main stress (as in example (5)) signals a declarative intonation in Hong Kong English, even if a low boundary tone is absent (Gussenhoven 2014). But this is not reported in either Cantonese or English. Whquestions are signalled by a high initial tone on the wh-word in HKE, like in English. Furthermore, wh-questions have either a high (small rise) or a low boundary tone on the final syllable with a relatively flat final tone, which is not observed in Cantonese or English. The declination in wh-questions is less steep than in statements (Chen \& Mok 2015). Yes-no questions have a high boundary tone with a final rise smaller than that of echo questions (Chen \& Mok 2015). Finally, echo questions are cued by a high final boundary tone (Chen \& Mok 2015; Han 2013), like in English and in Cantonese. The final rise in echo questions is larger than that in yes-no questions. The final rise in HKE questions occurs from the penultimate syllable while in Hong Kong Cantonese it starts from the final syllable.

A comparison between the intonation of native English, HKE, and Hong Kong Cantonese is shown below.

TABLE 4.

COMPARISON BETWEen NATIVE ENGLish, HKe, AND HKC (NA MEANS 'NOT APPLICABLE’; $\uparrow$ FOR Rise, $\downarrow$ For FALL)

\begin{tabular}{|c|c|c|c|c|c|}
\hline Varieties & Question types & Declination & Boundary & $\begin{array}{l}\text { Place of final } \\
\text { rise/fall }\end{array}$ & Global raising \\
\hline Native E & \multirow{3}{*}{ Statement } & \multirow{3}{*}{ Yes } & $\mathrm{L} \%$ & $\begin{array}{c}\text { After the last } \\
\text { accented syllable } \downarrow\end{array}$ & \multirow{6}{*}{ NA } \\
\hline HKE & & & $\mathrm{L} \%$ or $\%$ & $\begin{array}{c}\text { Final syllable or last } \\
\text { L } \downarrow\end{array}$ & \\
\hline HKC & & & $\mathrm{L} \%$ & Final syllable $\downarrow$ & \\
\hline Native E & \multirow{3}{*}{ Wh-questions } & Yes & \multirow{3}{*}{$\mathrm{H} \%$ or $\mathrm{L} \%$} & The final $\mathrm{L}^{-} \downarrow$ & \\
\hline HKE & & $\begin{array}{l}\text { Probably, smaller than } \\
\text { that of statements }\end{array}$ & & $\begin{array}{c}\text { Penultimate syllable } \\
\uparrow \\
\text { Final syllable } \downarrow\end{array}$ & \\
\hline $\mathrm{HKC}$ & & Yes & & $\begin{array}{l}\text { Second part of the } \\
\text { last syllable } \uparrow\end{array}$ & \\
\hline Native $\mathrm{E}$ & \multirow{3}{*}{ Yes-no questions } & \multirow{3}{*}{ Yes } & \multirow{2}{*}{$\mathrm{H} \%$} & $\begin{array}{c}\text { The first accented } \\
\text { syllable } \uparrow\end{array}$ & Yes \\
\hline HKE & & & & $\begin{array}{c}\text { Penultimate syllable } \\
\uparrow\end{array}$ & \multirow[b]{2}{*}{ No } \\
\hline HKC & & & Optional H\% & $\begin{array}{c}\text { Second part of the } \\
\text { last syllable } \uparrow\end{array}$ & \\
\hline Native E & \multirow{3}{*}{ Echo questions } & \multirow{3}{*}{ Yes } & \multirow{3}{*}{$\mathrm{H} \%$} & The final $\mathrm{H}^{-} \uparrow$ & Yes \\
\hline HKE & & & & $\begin{array}{c}\text { Penultimate syllable } \\
\uparrow\end{array}$ & \multirow[t]{2}{*}{ No } \\
\hline $\mathrm{HKC}$ & & & & Final syllable $\uparrow$ & \\
\hline
\end{tabular}

\section{EXPERIMENTAL APPROACH}

Based on the historical differences and the language contact with British settlers, HKE and GZE intonation might be significantly different. Alternatively, based on the common native dialect, which is sometimes considered as 
phonologically homogeneous, HKE and GZE intonation might also be similar. The intonational system of HKE is relatively well-described, but that of GZE in completely under-investigated. We therefore recorded native speakers of Guangzhou Cantonese in English and compared their English to HKE intonation as described in the literature. We also recorded these speakers in their native language to investigate transfer effects from their native language to L2 English. We recorded and analysed the same four intonation types in Guangzhou Cantonese (GC) and Guangzhou-accented English (GZE). In total, 306 English sentences produced by 18 speakers were analysed.

\section{Materials}

To obtain natural intonation (as far as possible), we designed a picture description task. The sentences we targeted were the four sentence types we discussed above: statements, wh-questions, yes-no questions and echo questions. We targeted six wh-questions, three yes-no questions, six statements, and five echo questions. A picture was made to elicit each sentence, with conversation bubbles containing keywords in English.

Here it is necessary to note that the categorization of the sentence types does not necessarily stipulate that there are 'canonical', default intonation patterns corresponding to different sentence types (e.g. statements and wh-questions end with a falling contour while yes/no questions terminates in a rise). Rather, innovations are added to such kinds of conventions, the breach of which may rouse native listeners to perceive something unusual or different from the norm. For example, wh-questions produced with a final rise can be interpreted as having a softening, sometimes patronizing effect (Reed \& Levis 2015).

Subjects

Eighteen Guangzhou Cantonese speakers, nine males and nine females, aged between 19 and 21, and one male of 25 were paid to participate in the study. All participants were college students not following a major in English.

Design

The experiment consisted of a PowerPoint slide show of twenty slides, each with a picture and keywords in English. The same slides were used once to elicit English and once to elicit Cantonese. The twenty sentences were pseudorandomized such that the sentences with park and bank alternated. A list of English model sentences (see Appendix) was available for the participants to prepare before the recording.

\section{Procedure}

The experiment was conducted in quiet rooms at Guangzhou University and Guangdong University of Foreign Studies. Before the recording, the participants received instructions to describe each picture by a sentence according to the keywords provided in conversation bubbles. They were asked to repeat the sentence if they made a mistake or hesitated. The sentences were recorded using a Tascam DR-05 recorder and a Rode Smartlav microphone. During the recording, the experimenter left the room. The participants went through the slides twice: the first time they described the pictures in English and the second time in Cantonese (they also repeated it in Mandarin, which will be analysed in a larger study). After the picture descriptions, they read a list of the target sentences. After the whole experiment, the participants' linguistic background was elicited, such as the participants' major, a self-assessment of their English level, their frequency of usage of languages and the linguistic background of the participants' parents.

Analysis

We adopted the Hong Kong Cantonese ToBI labelling conventions (Wong et al. 2005) to label lexical tones and intonation in Guangzhou Cantonese. For the boundary tones, we used the conventional ' $H$ ', ' $L$ ' and ' $\%$ ' notation proposed by Pierrehumbert (1980), which are also used in the ToBI conventions for other languages. We analysed the boundary tones, declination, and global raising using the Praat script ProsodyPro (Xu 2013).

\section{RESULTS}

\section{Guangzhou Cantonese intonation}

Previously in the subsection of HKC, we described Cantonese, including Hong Kong and Guangzhou Cantonese as a single variety. Our observation of Guangzhou Cantonese intonation confirms that they do share the same intonation system, which motivates the hypothesis that HKE and GZE may share the same intonational system.

Just like in Hong Kong Cantonese (see HKC), all sentence types in Guangzhou Cantonese have declination. Statements (Figure 1) have a low boundary tone and wh-questions have either a high (Figure 2) or a low boundary tone. 


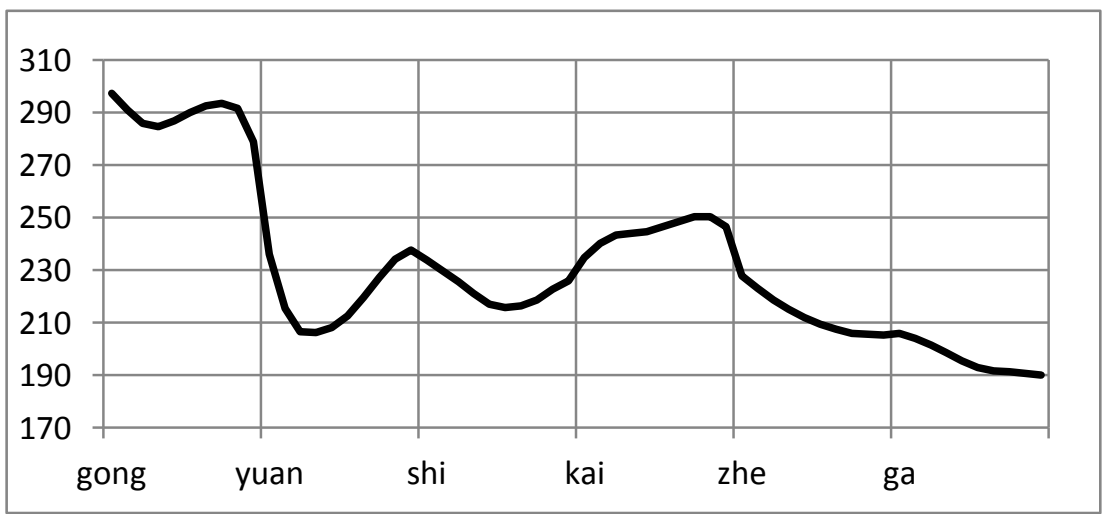

Figure 1. F0 contour of Guangzhou Cantonese statements 'The park is open’

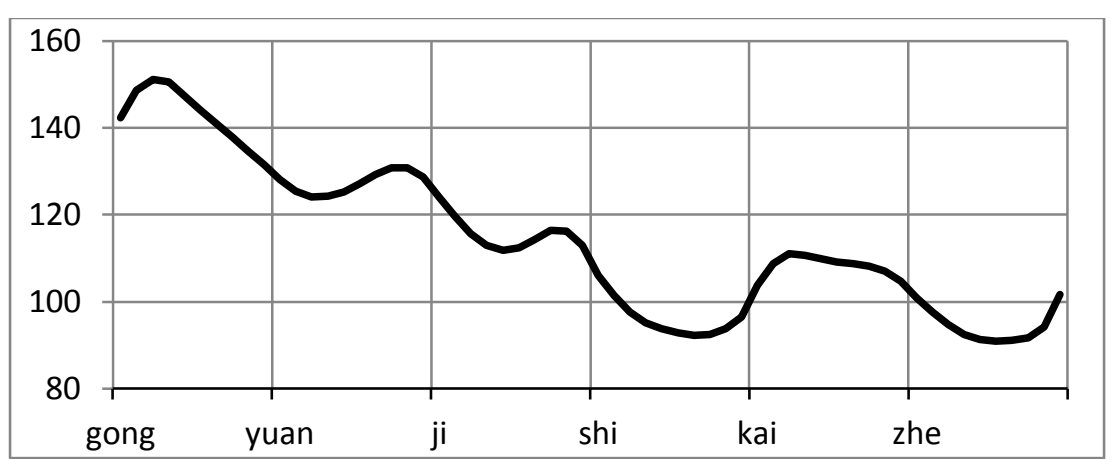

Figure 2. F0 contour in GZ Cantonese wh-questions 'When is the bank open?'

We also observe an optional $\mathrm{H} \%$ in yes-no questions in Guangzhou Cantonese (see Figure 3 for an example).

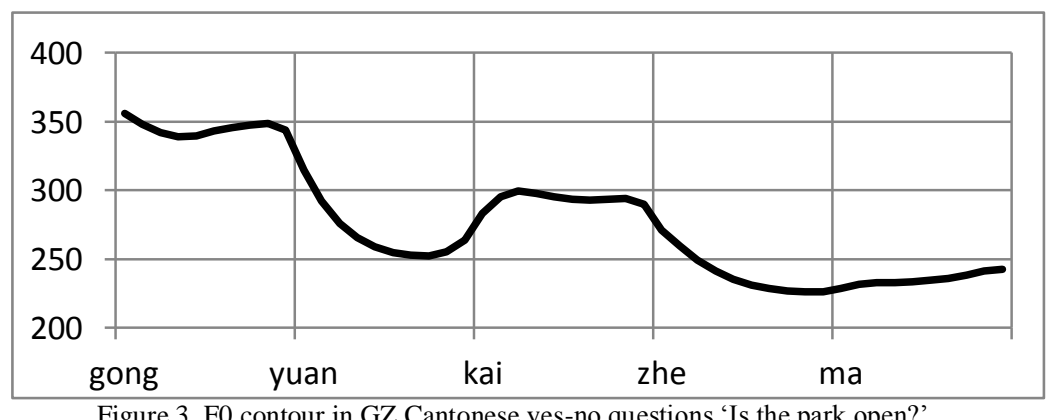

Finally, echo questions are distinguished by short and long sentences. In both we find declination and a high final boundary tone, again similar to HK Cantonese. However, short echo questions have a global raise compared with statements (Figure 4), which we do not find in long echo questions (Figure 5). In the long echo questions, we observe a final rise starting at the penultimate syllable. This may be different from echo questions in Hong Kong Cantonese, which are reported to have no global raising but instead have a final rise starting at the final syllable. 


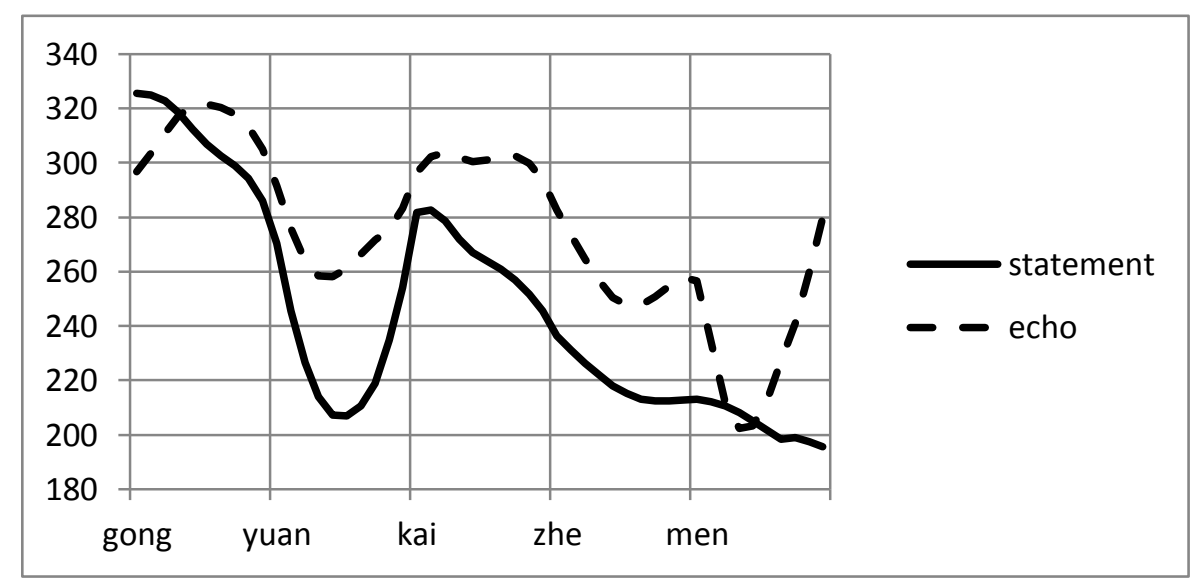

Figure 4. F0 contour of GZ Cantonese short echo questions vs statements 'The park is open'

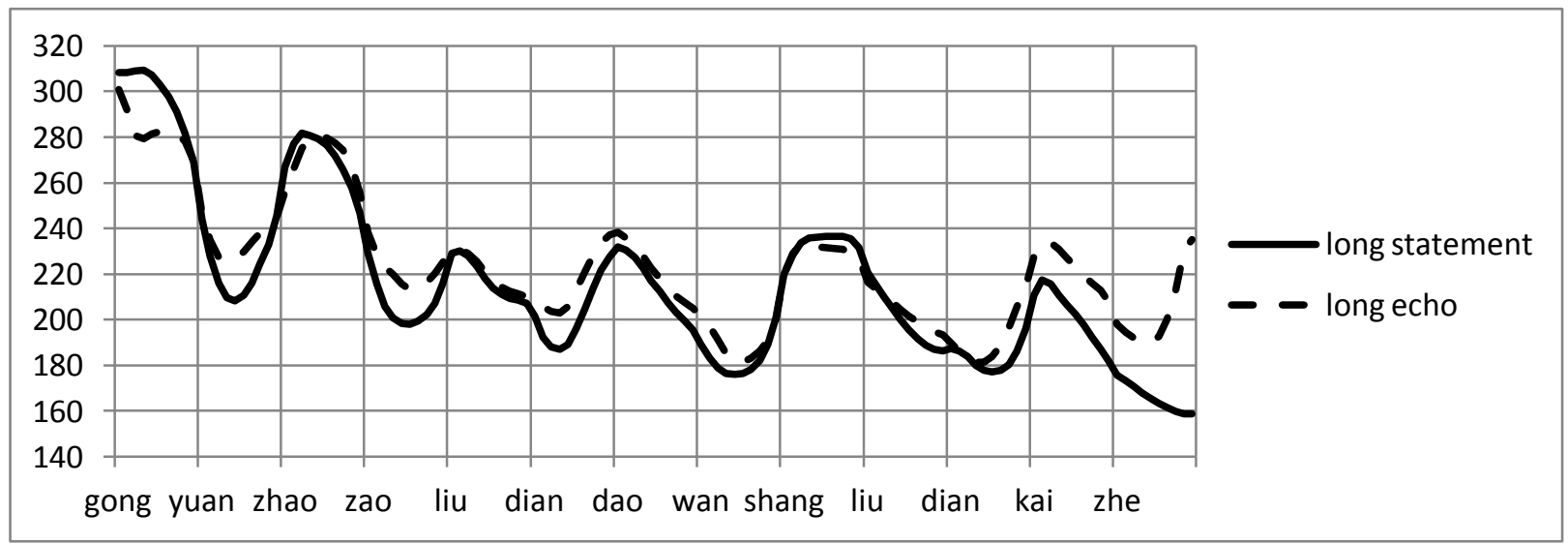

Figure 5. F0 contour of GZ Cantonese long echo questions vs. long statements 'The park is open from six a.m. to six p.m.'

A comparison between HK and GZ Cantonese intonation is shown in Table 5 below.

TABLE 5.

COMPARISON BETWEen HKC AND GZC (NA MEANS ‘Not APPliCABLE’ $\uparrow$ FOR Rise, $\downarrow$ For FALL)

\begin{tabular}{|c|c|c|c|c|c|c|c|c|c|}
\hline \multirow{2}{*}{\multicolumn{2}{|c|}{ Cantonese Intonation }} & \multicolumn{2}{|c|}{ Declination } & \multicolumn{2}{|c|}{ Boundary } & \multicolumn{2}{|c|}{ Place of final rise/fall } & \multicolumn{2}{|c|}{ Global raising } \\
\hline & & HK & GZ & HK & GZ & HK & GZ & $\mathrm{HK}$ & GZ \\
\hline \multicolumn{2}{|l|}{ Statements } & \multirow{5}{*}{ Yes } & & \multicolumn{2}{|l|}{$\mathrm{L} \%$} & \multicolumn{2}{|l|}{ Final syllable $\downarrow$} & \multicolumn{2}{|l|}{ NA } \\
\hline \multicolumn{2}{|l|}{ Wh-questions } & & & \multicolumn{2}{|c|}{$\mathrm{H} \%$ or $\mathrm{L} \%$} & \multicolumn{2}{|c|}{ Second part of the final syllable $\uparrow$} & \multicolumn{2}{|l|}{ NA } \\
\hline \multicolumn{2}{|l|}{ Yes-no questions } & & & \multicolumn{2}{|c|}{ Optional H\% } & \multicolumn{2}{|c|}{ Second part of the final syllable $\uparrow$} & \multicolumn{2}{|l|}{ No } \\
\hline \multirow[t]{2}{*}{ Echo-questions } & short & & & \multirow{2}{*}{\multicolumn{2}{|c|}{$\mathrm{H} \%$}} & \multicolumn{2}{|l|}{ Final syllable $\uparrow$} & No & Yes \\
\hline & long & & & & & Final syllable $\uparrow$ & $\begin{array}{l}\text { Penultimate } \\
\text { syllable } \uparrow\end{array}$ & No & \\
\hline
\end{tabular}

So, as for intonation, GZ and HK Cantonese only differ slightly in echo questions. The following subsection shows the results of GZE intonation and a comparison between GZE vs. HKE, and GZE vs. native English.

GZE vs. HKE

A comparison between GZE and HKE shows large similarities between the two varieties.

Declination in statements can take two patterns. Short statements have a clear declination, as shown in Figure 6, which mirrors that for statements in HKE. Long statements, however, show no declination, which is different from HKE. Similar to HKE intonation, a low boundary tone. Also similar to HKE, L\% occurs on the final syllable in GZE. So as for statements, only declination in long sentences appears to be deviant from HKE. 


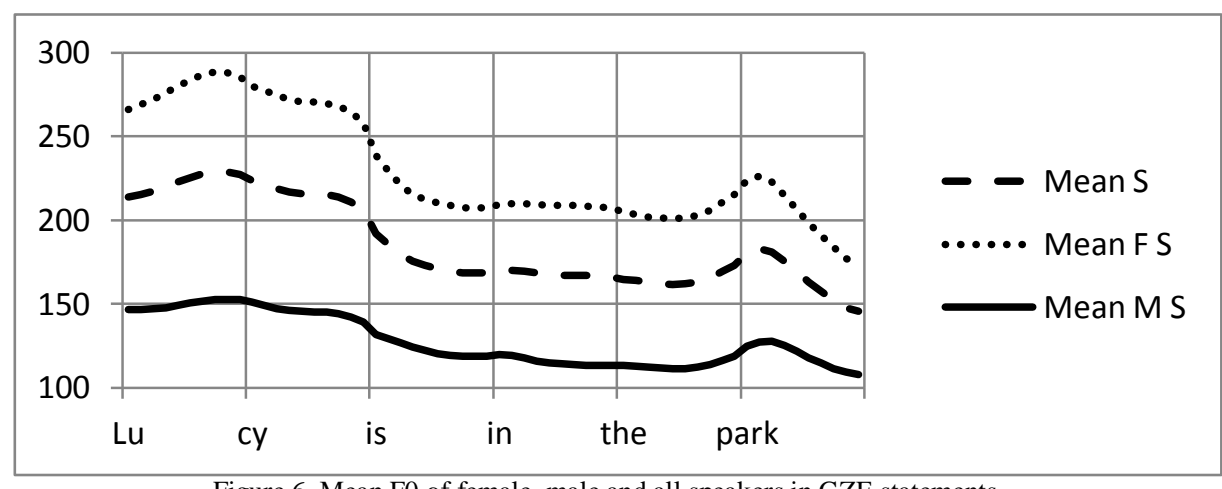

Figure 6. Mean F0 of female, male and all speakers in GZE statements

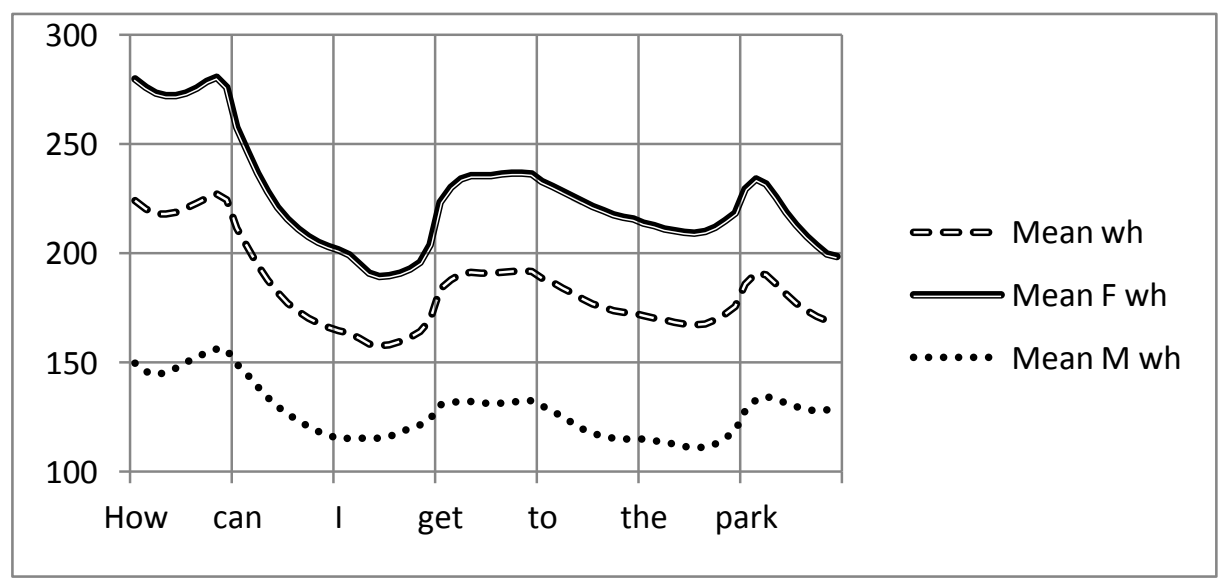

Figure 7. Mean F0 of GZE wh-questions

Wh-questions in GZE do not consistently show declination. Even if there is declination, the declination is not steep, just like in HKE, cf. Chen \& Mok (2015). Wh-questions start with a high boundary tone followed by a fall (see Figure 7). They typically end with a low or a high boundary tone, the first being more frequent (corroborating Ye 2015 for HKE, although Ye mistook the high boundary tone for an error). This variation between $\mathrm{L} \%$ and $\mathrm{H} \%$ is also observed by Chen \& Mok (2015) for HKE. The final boundary tone can be L\% or H\%, falling on the final syllable. Similarly, HKE has the final fall on the last syllable or the rise on the penultimate syllable.

We also observe the final rise with relatively flat tone like in HKE (Chen \& Mok 2015). Therefore, for the intonation of wh-questions we cannot observe substantial differences between HKE and GZE.

Yes-no questions in GZE show no declination or very slight declination. This is different from HKE, in which the F0 contours of yes-no questions largely overlap that with statements — which do have declination — until the penultimate syllable. GZE and HKE yes-no questions have an H\% (Figure 8) and the final rise also starts on the penultimate syllable. The mean F0 contour of yes-no questions for all speakers is given in Figure 9. As in HKE, we do not observe a global raising in GZE. So the only difference between HKE and GZE regarding yes-no questions is that the former shows more declination.

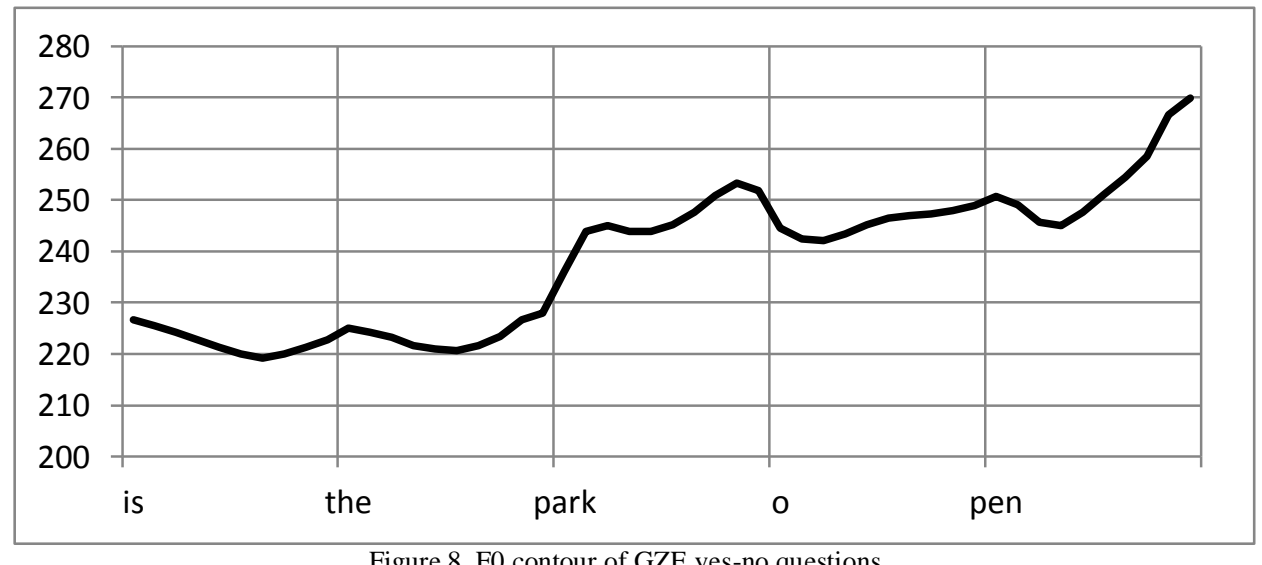

Figure 8. F0 contour of GZE yes-no questions 


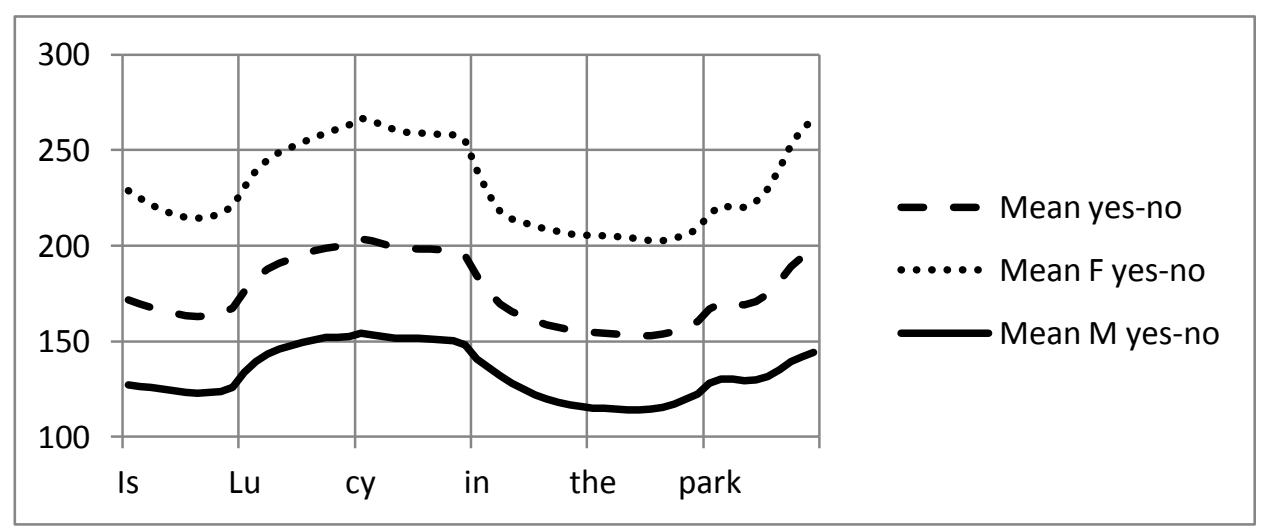

Figure 9. Mean F0 of female, male, and all speakers in GZE yes-no questions

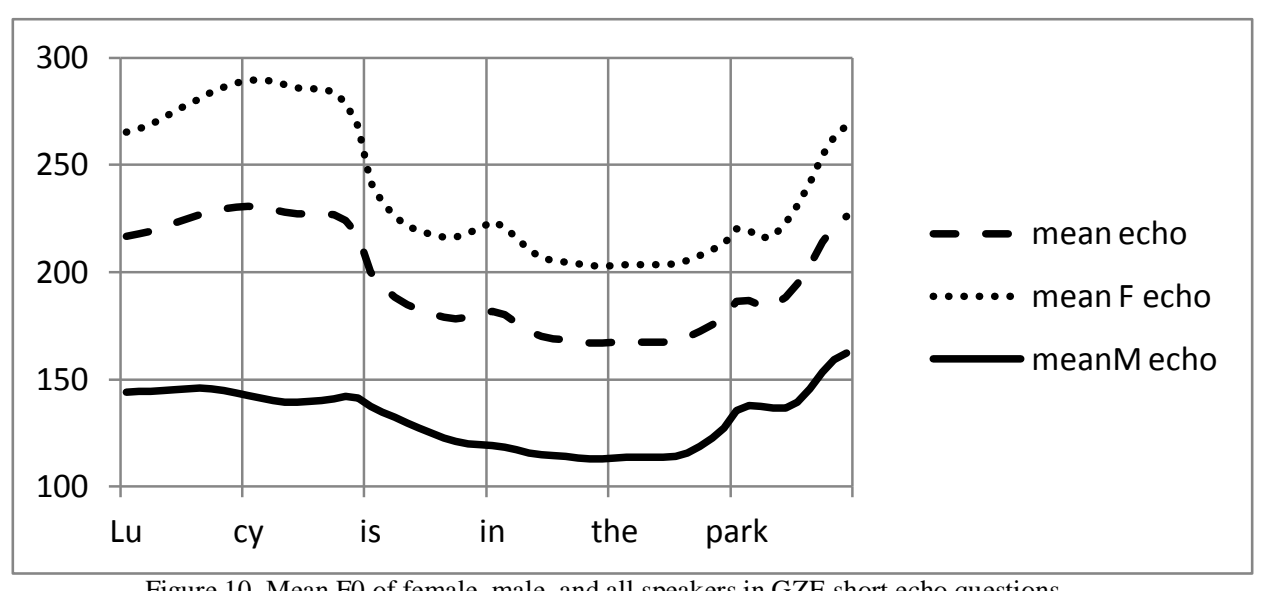

Figure 10. Mean F0 of female, male, and all speakers in GZE short echo questions

Finally, echo questions are realized with an H\%, as is also observed in HKE (Figure 10). Short echo questions have a slightly smaller declination than statements (Figure 11). However, long statements and long echo questions largely overlap until the final or penultimate syllable, without showing declination (Figure 12). This is different from HKE, in which the echo questions overlap with the statements until penultimate syllable. Echo questions don't show global raising in GZE, which is the same with HKE. Therefore, for echo questions GZE differ from HKE mainly in declination.

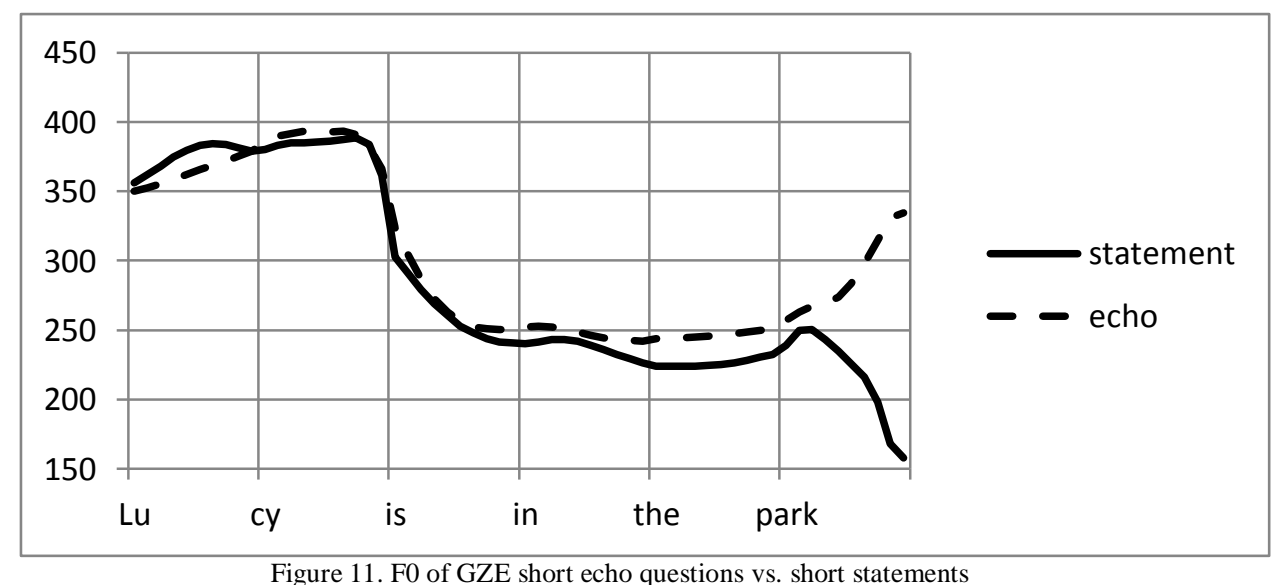

Figure 11. F0 of GZE short echo questions vs. short statements 


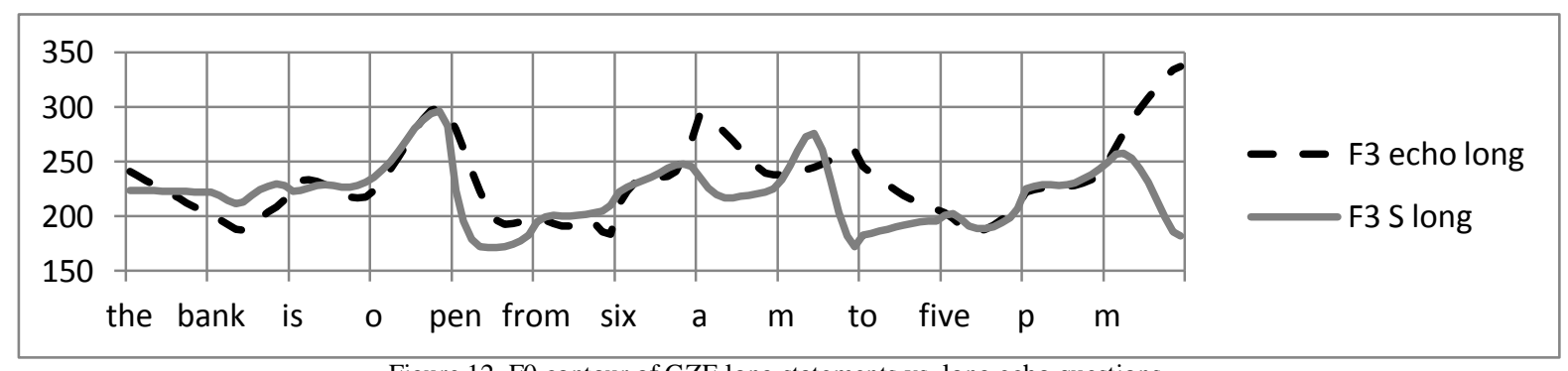

Figure 12. F0 contour of GZE long statements vs. long echo questions

We summarize the four sentence types in Figure 13.

Figure 13 shows overlap of the F0 contours of statements and echo questions until the ultimate or sometimes penultimate syllable. The latter pattern is also reported for HKE (Chen \& Mok 2015; Xu \& Mok 2011) (see HKE). For the final syllable, the intonation contour of echo questions overlaps with that of yes-no questions (see also Figure 14). This is different from Chen \& Mok's (2015) finding that echo questions in HKE have a higher final boundary tone than yes-no questions.

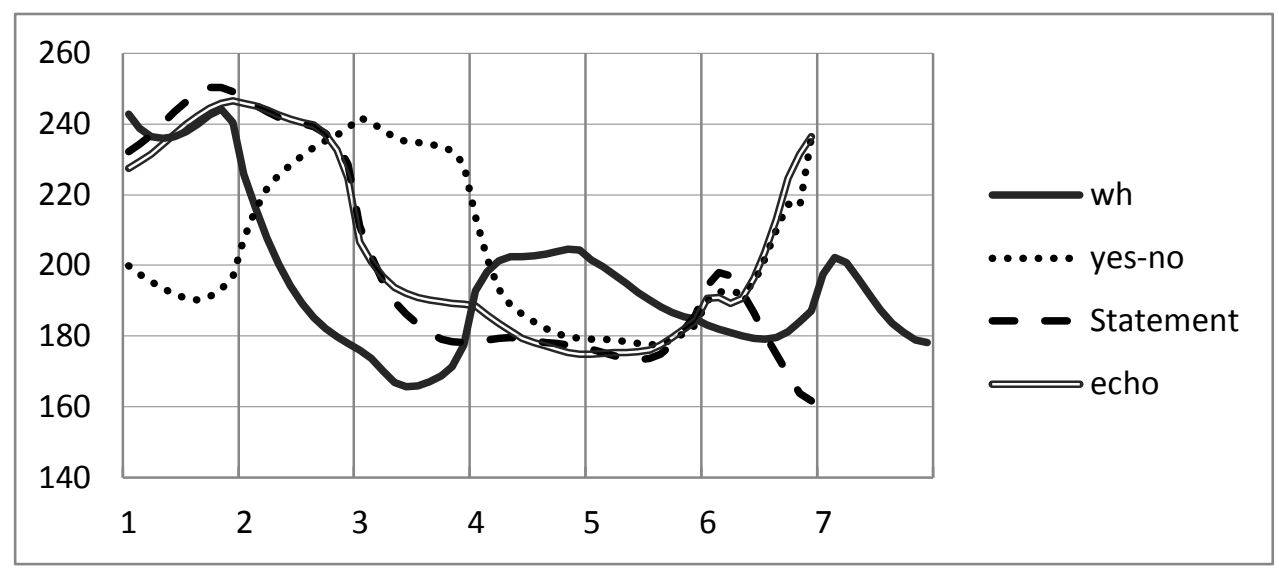

Figure 13. Mean F0 of all four sentence types

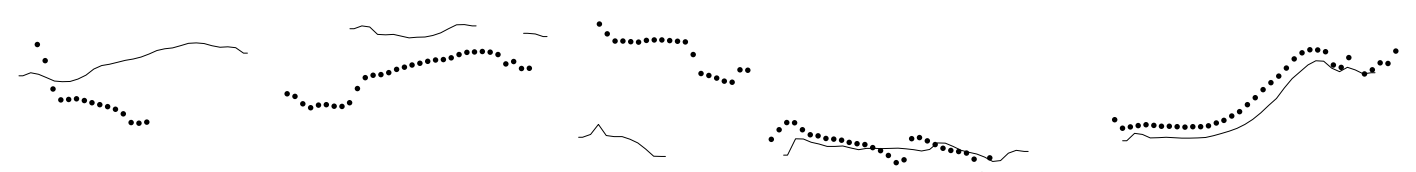

Figure 14. Time-normalized normalized pitch contour of 'Is Lucy in the park?' (speckle) and 'Lucy is in the park?' (line) in GZE

Our results show that GZE and HKE are very similar, with only slight differences.

Table 6 displays the differences between HKE and GZE, which mainly lie in declination: GZE tends to have less declination than HKE.

TABLE 6.

COMPARISON BETWEEN HKE AND GZE

\begin{tabular}{|c|c|c|c|c|c|c|}
\hline Sentence types & \multicolumn{2}{|c|}{ Varieties } & Declination & Boundary & Place of final rise/fall & $\begin{array}{l}\text { Global } \\
\text { raising }\end{array}$ \\
\hline \multirow[t]{2}{*}{ Statements } & \multicolumn{2}{|l|}{ HKE } & Yes & & & \\
\hline & \multicolumn{2}{|l|}{ GZE } & Not for long statements & & & \\
\hline \multirow[t]{2}{*}{ Wh-questions } & \multicolumn{2}{|l|}{ HKE } & & & & \\
\hline & \multicolumn{2}{|l|}{ GZE } & & & & \\
\hline \multirow[t]{2}{*}{ Yes-no questions } & \multicolumn{2}{|l|}{ HKE } & Yes & & & \\
\hline & \multicolumn{2}{|l|}{ GZE } & $\begin{array}{l}\text { No declination, or slight } \\
\text { declination }\end{array}$ & & & \\
\hline \multirow[t]{3}{*}{ Echo questions } & \multicolumn{2}{|l|}{ HKE } & $\begin{array}{l}\text { Yes, the same as in } \\
\text { statements }\end{array}$ & $\begin{array}{l}\mathrm{H} \% \text { (higher than in yes- } \\
\text { no questions) }\end{array}$ & Penultimate syllable & \\
\hline & \multirow[t]{2}{*}{ GZE } & Short & $\begin{array}{l}\text { Yes, smaller than in } \\
\text { statements }\end{array}$ & \multirow[t]{2}{*}{$\begin{array}{l}\mathrm{H} \% \text { (no difference found } \\
\text { than in yes-no questions) }\end{array}$} & \multirow[t]{2}{*}{$\begin{array}{l}\text { Final or Penultimate } \\
\text { syllable }\end{array}$} & \\
\hline & & long & No & & & \\
\hline
\end{tabular}


Knowing the similarities and dissimilarities between GZE and HKE intonation, we now turn towards the question whether HKE and GZE reach the target intonation of English.

GZE vs. native English

A comparison between native English, GZE, HKZ, and Cantonese shows that the deviations of GZE and HKZ from native English sometimes point to the influence from Cantonese but sometimes don't. Both native English and Cantonese have L\% for statements, but HKE and GZE sometimes lack a boundary tone. Declination is realized in whquestions in native English and Cantonese, but not consistently in HKE and GZE wh-questions and in yes-no questions in GZE. Besides, when statements and echo questions are long, they show no declination in GZE.

The rest of the deviations of HKE and GZE from native English recall an echo from the speakers' native Cantonese: 1) the place of final rise or fall in HKE and GZE always takes place on the last one or two syllables like Cantonese does 2) while in native English the echo questions have an overall higher F0 and a global raising in the last domain of the sentence (Chow(2002, cited in Chen \& Mok 2015; Clements 1990, O'Shaughnessy 1979), there is an overall higher pitch level but no global raising in yes-no questions or echo questions in HKE and GZE like in most cases in Cantonese.

Besides the above-mentioned aspects of intonation, we observed some accents in the participants' utterances, which is not expected in native English. Content words appear to be consistently accented $\left(\mathrm{H}^{*}\right)$. For instance, the word Lucy is frequently accented in all sentence types, as if the first syllable of Lucy had an intrinsic pitch height. The words park and bank also have a relatively stable pitch level. Similarly, in the sentence "the man under the tree is Lucy's father", high tones appear on the second syllables of under and Lucy, which would be completely unexpected in native speakers.

These unexpected accents are explained as a result of the transfer of the Cantonese tone system (Luke 2000). In Cantonese, function words may be realized with some tone (Wong et al. 2005), of which this may be an effect. In some speakers, content words (frequently including prepositions) and words in a particular context or position (such as in phrase boundary marking non-finality) may tend to attract a pitch accent, because these words are lexically important and needs to be marked in a certain way. The pitch accents of words are subject to down-step and boundary tones too.

The high pitch assigned may optionally copy or spread to the next syllable within the word such as in the word Lucy, which is realized either as $\mathrm{HL}$ or $\mathrm{HH}$, the former of which tends to appear in a final position, and the latter in non-final position. But the assignment of pitch accents in Cantonese English is much more complicated than can be elucidated here.

\section{CONCLUSION}

We investigated whether GZE and HKE intonation are comparable or whether they show clear differences. Given that HKE is to a certain extent a standardized variety, developed by long term language contact, and GZE is a second language variety in which apparent negative transfer effects both at the segmental and the suprasegmental level are reported, one could expect the two to have clearly different intonation patterns. On the other hand, since the native varieties have claimed to be more or less the same, one could expect the same patterns of native language transfer. To investigate this matter, we studied the intonation of four sentence types in GZE: statements, wh-questions, yes-no questions and echo questions, and compared these to the well-described intonation in HKE.

As far as the investigated aspects of intonation are concerned, HKE and GZE share large similarity in terms of declination and boundary tones, and the possible influence from Cantonese to not show a global raising in yes-no questions or echo questions. The findings suggest that there are no significant differences between the two varieties of English. They shared similarities in boundary tones, and places of final rise or fall in all four sentence types, and both showed no global raising in yes-no or echo questions, different from native English. The only differences are that Hong Kong speakers show more declination than Guangzhou speakers in English long statements, yes-no questions and echo questions and that the boundary tone in echo questions is higher than that in yes-no questions in HKE but it is the same height in GZE. Since both in native English and in Cantonese there is declination, it is unclear why Guangzhou speakers show less steep or even no declination in English. Besides, some words show unexpected accents. We suggest tonal assignment in such words is due to a transfer effect of Cantonese prosodic system.

Our findings cast doubt on Schneider's model of standardization, in which linguistic structure is seen as one of the criteria for classification of an English variety into one of the five phases, for there are other criteria as we explained in the section of background information and these criteria are likely to be very similar to those of L2 acquisition. The results of our research points towards HKE as being a second language, with an accent of Cantonese in a wider sense; including Hong Kong and Guangzhou and other areas where Cantonese is spoken. English has a different history and social function in Hong Kong than in Guangzhou, with important lexical differences, and early borrowings in HKE that don't occur in GZE (Li 1999a). But with respect to intonation there turns out to be little difference between HKE and GZE.

Future research will explore the rhythmic patterns and tone spreading patterns in both varieties to see in what other ways native Cantonese affects speakers' L2 English prosody, both in Hong Kong and in Guangzhou. We will also compare English intonation produced by speakers from Guangzhou with those from other mainland regions, including Beijing. Deterding et al. (2008) reported that Cantonese features as well as British and American English features affected HKE pronunciation at the segmental level. Of course, complementary research is needed to compare other 
suprasegmental factors (e.g. the tonal systems, phrasing) or segmental ones. Most of all, perception experiments are needed to examine the intonation of HKE and GZE as well as Chinese English in other regions of China.

\section{REFERENCES}

[1] Bartels, Christine. (2013). The intonation of English statements and questions: A compositional interpretation. New York and London: Routledge.

[2] Bauer, Robert S. \& Paul K. Benedict. (1997). Modern Cantonese Phonology. Berlin and New York: Mouton de Gruyter.

[3] Beckman, Mary E. \& Gayle Ayers. (1997). Guidelines for ToBI labelling. Columbus, OH: The OSU Research Foundation.

[4] Beckman, Mary E. \& Julia Hirschberg. (1994). The ToBI annotation conventions. Columbus, OH: Ohio State University.

[5] Bolton, Kingsley. (2000). The sociolinguistics of Hong Kong and the space for Hong Kong English. World Englishes, 19(3), 265-285.

[6] Bolton, Kingsley. (2002). Chinese Englishes: From Canton jargon to global English. World Englishes, 21(2), 181-199.

[7] Bolton, Kingsley. (2006). Chinese Englishes: A sociolinguistic history. Cambridge: Cambridge University Press.

[8] Bolton, Kingsley. (2011). Language policy and planning in Hong Kong: Colonial and post-colonial perspectives. Applied Linguistics Review, 2, 51-74.

[9] Bolton, Kingsley \& Helen Kwok. (1990). The dynamics of the Hong Kong accent: Social identity and sociolinguistic description. Journal of Asian Pacific Communication, 1(1), 147-172.

[10] Brown, Gillian, Karen L. Currie \& Joanne Kenworthy. (2015). Questions of intonation. London: Routledge.

[11] Bu, Youhong. (2016). Chinese EFL learners' problems in their English intonation. Foreign Language Teaching and Research, 48(4), 569-582, 641

[12] Butler, Susan. (1997). Corpus of English in Southeast Asia: Implications for a regional dictionary. In Maria Lourdes S. Bautista (ed.), English is an Asian language: The Philippine context, 103-24. Sydney: Macquarie Library.

[13] Chen, Shuwen, Peggy Pik Ki Mok. (2015). Question intonation in Hong Kong English: Interaction between Cantonese and English. Paper presented at the Conference of the International Phonetic Association.

[14] Cheung, Winnie H.Y. (2009). Span of high tones in Hong Kong English. Proceedings of the Annual Meeting of the Berkeley Linguistics Society, 35, 72-82.

[15] Chow, Shuen. (2002). A phonetic study of the intonation in Hong Kong Cantonese. M.Phil dissertation, City University of Hong Kong.

[16] Clements, George N. (1990). The status of register in intonation theory: Comments on the papers by Ladd and by Inkelas and Leben. In John Kingston \& Mary E. Beckman, (eds.), Papers in laboratory phonology, 1, 58-71. Cambridge: Cambridge University Press.

[17] Cohen, Antonie \& René Collier. (1982). Declination: construct or intrinsic feature of speech pitch? Phonetica, 39(4-5), 254-273.

[18] Collins, Beverley \& Inger Mees. (2003). The phonetics of English and Dutch, 5th ed. Leiden: Brill.

[19] Cruttenden, Alan. (1997). Intonation. Cambridge: Cambridge University Press.

[20] Crystal, David. (1976). Prosodic systems and intonation in English. Cambridge: Cambridge University Press.

[21] Deterding, David, Jennie Wong \& Andy Kirkpatrick. (2008). The pronunciation of Hong Kong English. English World-Wide, 29(2), 148-175.

[22] Evans, Stephen. (2011a). Hong Kong English and the professional world. World Englishes, 30(3), 293-316.

[23] Evans, Stephen. (2011b). Hong Kong English: The growing pains of a new variety. Asian Englishes, 14(1), 22-45.

[24] Evans, Stephen. (2013). The long march to biliteracy and trilingualism: Language policy in Hong Kong education since the handover. Annual Review of Applied Linguistics, 33, 302-324.

[25] Everett, Caleb, Damián E. Blasí \& Seán G. Roberts. (2016). Language evolution and climate: the case of desiccation and tone. Journal of Language Evolution, 1(1), 33-46.

[26] Fox, Anthony, Kang-Kwong Luke \& Owen Nancarrow. (2008). Aspects of intonation in Cantonese. Journal of Chinese Linguistics, 36(2), 333-367.

[27] Fry, D. B. (1968). Manual of phonetics. Amsterdam: North-Holland.

[28] Fu, Gail S. (1987). The Hong Kong bilingual. In Robert Lord \& Helen N. L Cheng (eds.), Language education in Hong Kong, 27-50. Hong Kong: Chinese University Press.

[29] Groves, Julie M. (2011). 'Linguistic schizophrenia' in Hong Kong: Hong Kong English comes of age. English Today, 27(4), 3342.

[30] Gussenhoven, Carlos. (2004). The phonology of tone and intonation. Cambridge: Cambridge University Press.

[31] Gussenhoven, Carlos. (2012). Tone and intonation in Cantonese English. In Proceedings of the Third International Symposium on Tonal Aspects of Languages. Nanjing: International Speech Communication Association.

[32] Gussenhoven, Carlos. (2014). On the intonation of tonal varieties of English. Ms, Radboud University Nijmegen.

[33] Gussenhoven, Carlos \& Peter van der Vliet. (1999). The phonology of tone and intonation in the Dutch dialect of Venlo. Journal of Linguistics, 35(1), 99-135.

[34] Han, Weixin. (2013). A pilot study in Hong Kong Cantonese. Tianjin: Nankai University.

[35] Han, Yanmei. (2012). An analysis of the language attitude and self-identification of elementary school students in Guangzhou. Journal of Southwest Agricultural University (Section Social Sciences), 10, 201-205.

[36] Hirst, Daniel \& Albert Di Cristo. (1998). Intonation systems: A survey of twenty languages. Cambridge: Cambridge University Press.

[37] Huang, Xianjun, Lu Gao, Yang Yufan \&, Lv Shi'nan. (2009). An experimental study on declination in Chinese intonation. Acta Acustica, 2, 158-166.

[38] Hung, Tony T. N. (2000). Towards a phonology of Hong Kong English. World Englishes, 19(3), 337-356.

[39] Johnson, Robert Keith. (1994). Language policy and planning in Hong Kong. Annual Review of Applied Linguistics, 14, 177199. 
[40] Jun, Sun-Ah. (2006). Prosodic typology: The phonology of intonation and phrasing. Oxford: Oxford University Press.

[41] Kirkpatrick, Andy. (2007). World Englishes. Cambridge: Cambridge University Press.

[42] Le Page, Robert Brock \& Andrée Tabouret-Keller. (1985). Acts of identity: Creole-based approaches to language and ethnicity. Cambridge: Cambridge University Press.

[43] Li, David C. S. (1999a). Linguistic convergence: Impact of English on Hong Kong Cantonese. Asian Englishes, 2, 5-36.

[44] Li, David C.S. (1999b). The functions and status of English in Hong Kong: A post-1997 update. English World-Wide, 20(1), 67110.

[45] Luke, Kang-kwong. (2000). Phonological re-interpretation: the assignment of Cantonese tones to English words. Paper presented at the 9th International Conference on Chinese Linguistics, National University of Singapore.

[46] Luke, Kang-kwong \& Jack C Richards. (1982). English in Hong Kong: functions and status. English World-Wide, 3(1), 47-64.

[47] Ma, Joan K. Y., Valter Ciocca \& Tara L. Whitehill. (2006). Quantitative analysis of intonation patterns in statements and questions in Cantonese. Proceedings of the 3rd International Conference on Speech Prosody, Dresden, Germany, 277-280.

[48] Mok, Peggy P. K. (2011). The acquisition of speech rhythm by three-year-old bilingual and monolingual children: Cantonese and English. Bilingualism: Language and Cognition, 14(4), 458-472.

[49] Mok, Peggy P. K, Zuo Donghui \& Peggy W. Y. Wong. (2013). Production and perception of a sound change in progress: Tone merging in Hong Kong Cantonese. Language Variation and Change, 25(3), 341-370.

[50] O'Shaughnessy, Douglas. (1979). Linguistic features in fundamental-frequency patterns. Journal of Phonetics, 7(2), 119-145.

[51] Pierrehumbert, Janet. (1980). The phonology and phonetics of English intonation. PhD dissertation, MIT.

[52] Reed, Marnie \& John Levis. (2015). The handbook of English pronunciation. London: Wiley.

[53] Safárová, Marie \& Marc Swerts. (2004). On recognition of declarative questions in English. Proceedings of the Speech Prosody Conference 2004.

[54] Schneider, Edgar W. (2007). Postcolonial English: Varieties around the world. Cambridge: Cambridge University Press.

[55] Setter, Jane. (2003). A comparison of speech rhythm in British and Hong Kong English, Proceedings of the 15th International Congress of Phonetic Sciences, 467-470.

[56] Setter, Jane, S. P. Cathy Wong \& Brian Hok-Shing Chan. (2010). Hong Kong English. Edinburgh: Edinburgh University Press.

[57] Sewell, Andrew \& Jason Chan. (2010). Patterns of variation in the consonantal phonology of Hong Kong English. English World-Wide, 31(2), 138-161.

[58] Shen, Xiaonan. (1990). The prosody of Mandarin Chinese. Berkeley, CA: University of California Press.

[59] Strik, Helmer \& Louis Boves. (1995). Downtrend in F0 and Psb. Journal of Phonetics, 23(1-2). 203-220.

[60] Tench, Paul. (2015). The intonation systems of English. London: Bloomsbury.

[61] van Heuven, Vincent J. \& Judith Haan. (2002). Temporal distribution of interrogativity markers in Dutch: A perceptual study. In Carlos Gussenhoven \& Natasha Warner (eds.), Laboratory phonology, 7, 61-86. Berlin and New York: Mouton de Gruyter.

[62] Vance, Timothy J. (1976). An experimental investigation of tone and intonation in Cantonese. Phonetica, 33(5), 368-392.

[63] Wenk, Brian J. (1985). Speech rhythms in second language acquisition. Language and Speech, 28(2), 157-175.

[64] Wong, Wai Yi P., Marjorie K. M. Chan \& Mary E. Beckman. (2005). An autosegmental-metrical analysis and prosodic annotation conventions for Cantonese. In: Sun-Ah Jun (ed.), Prosodic typology: The phonology of intonation and phrasing, 271-300. Oxford: Oxford University Press.

[65] Xu, Bo Robert \& Peggy Pik Ki Mok. (2011). Final rising and global raising in Cantonese intonation, Proceedings of the Seventeenth International Congress of the Phonetic Sciences, 2173-2176.

[66] Xu, Yi. (2013). ProsodyPro: A tool for large-scale systematic prosody analysis. In Brigitte Bigi \& Daniel Hirst (eds.), Proceedings of Tools and Resources for the Analysis of Speech Prosody (TRASP 2013). TRASP, Aix-en-Provence, 7-10.

[67] Ye, Yushan. (2015). An investigation of the English pronunciation of English majors in Cantonese areas-a case study of Guangzhou College of South China University of Technology. Journal of Heilongjiang College of Education, 34, 134-135.

[68] Yi, Bin. (2010). A study on English curriculum change of China's basic education during the thirty years of reform and opening up (1978-2008). PhD dissertation, Hunan Normal University.

[69] Zhan, Bohui. (2004). An outline of Yue dialects in Guangdong. Guangzhou: Jinan University Press.

[70] Zheng, Ding'ou. (1998). Language variation: a comparison between Hong Kong Cantonese and Guangzhou Cantonese. Studies of the Chinese Language, 1, 56-65.

Yunyun Ran was born in Chongqing, China in 1989. She received her PhD degree in English language and literature from Shanghai International Studies University, China in 2018.

She is currently a lecturer in the School of Foreign Languages, Shanghai University of Engineering Science, China. Her research interests include phonetics and psycholinguistics.

Dr. Ran was a visiting researcher at the Fryske Akademy (KNAW), the Netherlands, from 2016 to 2017.

Jeroen van de Weijer was born in Wijchen, the Netherlands in 1970. He is Distinguished Professor of English linguistics and $\mathrm{PhD}$ Supervisor at Shenzhen University.

He graduated from the University of Nijmegen in Holland and spent one year at University College London, after also having lived in the United States for one year. He received his Ph.D. in linguistics from Leiden University (Holland). Before coming to Shenzhen University, he taught at Leiden University and Shanghai International Studies University. His interest is in how linguistic patterns in the broadest possible sense are acquired (or learned), stored in memory, and used for language comprehension and production. This especially involves the fields of phonetics, phonology, linguistic variation, morphology, language acquisition and other areas of cognitive science. Wikipedia: http://en.wikipedia.org/wiki/Jeroen_van_de_Weijer 
Marjoleine Sloos was born in Leiden, the Netherlands in 1975. She is post-doctoral research fellow at the Fryske Akademy, a research institute funded by the Royal Netherlands Academy of Arts and Sciences.

She received her Ph.D. from Groningen University, after which she held postdoc and research/teaching positions at Arhus University (Denmark) and Tongji University (Shanghai, China). Her research interests include the phonetics and phonology of bilingualism and second language acquisition, and language variation and change. She has published widely and taught courses in various summer schools and research institutes. Information: http://marjoleinesloos.com/ 